\title{
The analgesic potency dose of remifentanil to minimize stress response induced by intubation and measurement uncertainty of Surgical Pleth Index
}

\author{
Ji H. PARK ${ }^{1}$, Dong-Hee KIM 2, Sun-Kook YOO ${ }^{3}$, Hyun-Jun LIM 4, Joo-Won LEE 5 , \\ Won-S. AHN 6 , Eun-Kyung LEE 7 , Byung-M. CHOI 5 *, Gyu-Jeong NOH 5,8
}

${ }^{1}$ Department of Anesthesiology and Pain Medicine, Hangang Sacred Heart Hospital, Hallym University College of Medicine, Seoul, South Korea; ${ }^{2}$ University of Ulsan College of Medicine, Seoul, South Korea; ${ }^{3}$ Department of Medical Engineering, Yonsei University College of Medicine, Seoul, South Korea; ${ }^{4}$ Graduate School of Biomedical Engineering, Yonsei University, Seoul, South Korea; ${ }^{5}$ Department of Anesthesiology and Pain Medicine, Asan Medical Center, University of Ulsan College of Medicine, Seoul, South Korea; ${ }^{B}$ Blood Flow Data Center, Kyunghee University Medical Center, Seoul, South Korea; ${ }^{7}$ Department of Statistics, Ewha Womans University, Seoul, South Korea; ${ }^{8}$ Department of Clinical Pharmacology and Therapeutics, Asan Medical Center, University of Ulsan College of Medicine, Seoul, South Korea

*Corresponding author: Byung-M. Choi, Department of Anesthesiology and Pain Medicine, Asan Medical Center, University of Ulsan College of Medicine, 388-1, Pungnap 2-dong, Songpa-gu, Seoul 138-736, South Korea. E-mail: byungmoonchoi7@gmail.com

\begin{abstract}
A B S T R A C T
BACKGROUND: The aim of this study was to evaluate the analgesic potency dose of remifentanil to maintain Surgical Pleth Index (SPI) values at less than 50 after intubation in patients undergoing general anesthesia with target-controlled infusion of propofol and remifentanil.

METHODS: We randomly allocated 120 patients to receive one of three remifentanil target effect-site concentrations $(5$, 7 , or $9 \mathrm{ng} \times \mathrm{mL}^{-1}$ ) during intubation. The target effect-site concentrations of propofol were adjusted within a range of 2.5-3 $\mu \mathrm{g} \times \mathrm{mL}^{-1}$ to maintain bispectral index values at less than 60 during anesthesia induction. A reusable SPI sensor was placed on the index finger of the arm, and the SPI values were continuously recorded. The predicted probability for maintaining the SPI values at less than 50 after intubation against the cumulative amount of remifentanil was analyzed using logistic regression. The measurands were the baseline SPI value in patients without pain scheduled for surgery, and the maximal SPI value after intubation in patients receiving remifentanil with a target effect-site concentration of $7 \mathrm{ng} \times \mathrm{mL}^{-1}$.

RESULTS: The estimated cumulative amount of remifentanil associated with a $50 \%$ and $95 \%$ probability of maintaining the SPI values at less than 50 after intubation were $135.0 \mu \mathrm{g}$ and $330.4 \mu \mathrm{g}$, respectively. The estimated expanded uncertainty for the baseline and maximal SPI values after intubation in patients scheduled for surgery were $54.9 \pm 44.4$ and $54.1 \pm 37.9$, respectively, which corresponded to a confidence level of approximately $95 \%$.

CONCLUSIONS: The analgesic potency dose of remifentanil to maintain SPI values at less than 50 after intubation was $135.0 \mu \mathrm{g}$.

(Cite this article as: Park JH, Kim DH, Yoo SK, Lim HJ, Lee JW, Ahn WS, et al. The analgesic potency dose of remifentanil to minimize stress response induced by intubation and measurement uncertainty of Surgical Pleth Index. Minerva Anestesiol 2018;84:546-55. DOI: 10.23736/S0375-9393.17.12065-1)
\end{abstract}

Key words: Intubation - Remifentanil - Stress, physiological - Surgery.

$\mathrm{T}$ arget-controlled infusion technology has been used to induce appropriate hypnotic

Comment in p. 534. and analgesic effects in patients undergoing general anesthesia. It enables precise and rapid titration of propofol and remifentanil during surgery. ${ }^{1}$ Reducing the intraoperative stress 
caused by nociceptive stimuli is important because it affects the patient's treatment outcome and length of hospital stay.2, 3 Direct laryngoscopy to facilitate orotracheal intubation is one of the most severe noxious stimuli evoked during general anesthesia. ${ }^{4}$ Such stimuli can be managed most effectively by providing analgesia. 5,6

The Surgical Pleth Index (SPI), which was developed to quantify intraoperative stress levels, has been shown to reflect noxious stimuli better than the heart rate or blood pressure. ${ }^{7-9}$ A previous study showed that the SPI was significantly correlated to the levels of stress hormones, including adrenocorticotropic hormone, cortisol, epinephrine, and norepinephrine. ${ }^{10}$ The SPI-guided analgesia strategy recommends maintaining the SPI values at less than 50 during general anesthesia. ${ }^{11,12}$ Previous studies have shown that, compared with the standard clinical analgesia practice, the SPI-guided analgesia strategy resulted in lower remifentanil consumption, more stable hemodynamics, and lower incidence of undesirable events. ${ }^{11,13}$ However, to the best of our knowledge, the analgesic potency dose of remifentanil to maintain the SPI values at less than 50 after intubation has not been evaluated in patients undergoing general anesthesia with target-controlled infusion of propofol and remifentanil.

Measurement is defined as a process of experimentally obtaining one or more values that can reasonably be attributed to a quantity. ${ }^{14}$ Generally, a measurement result consists of a single measured quantity value and a measurement uncertainty. ${ }^{15}$ This uncertainty represents a parameter characterizing the dispersion of the quantity values being attributed to a measurand based on the information used. ${ }^{14}$ An understanding of metrological concepts may be helpful when making clinical decisions. For example, a bispectral index value of 60 plays a role in making a guideline to the clinical doctors on maintaining anesthesia depth. However, when taking account of metrological concept, this reference value may be expressed as a range not as a single point.

The aim of this study was to evaluate the an- algesic potency dose of remifentanil to maintain the SPI values at less than 50 after intubation in patients scheduled for surgery under targetcontrolled infusion with different target effectsite concentrations of remifentanil. In addition to this purpose, the measurement uncertainty of the SPI was characterized in patients receiving an appropriate target effect-site concentration of remifentanil during intubation.

\section{Materials and methods}

\section{Patient population}

This single-center, prospective, randomized, single-blinded, and parallel-arm clinical trial was conducted between July and October 2016. This study was approved by the Asan Medical Centre Institutional Review Board (approval number: 2016-0477) and registered on an international clinical trials registry platform (http://cris.nih.go.kr, KCT0002080), and written informed consent was obtained from all patients. Patients who were between 20 and 80 years of age and scheduled for elective surgery were enrolled if their ASA physical status was I or II. The exclusion criteria were as follows: pregnancy or lactation, where pregnancy is defined as the state of a woman from conception, confirmed by a positive urine pregnancy test, until the termination of gestation; severely impaired respiratory function or respiratory depression status; clinically significant impairment of cardiovascular, hepatic, or renal function; risk of gastric aspiration on anesthesia induction; and Mallampati Score $\geq 4$. Patients were randomly allocated to receive one of three remifentanil target effectsite concentrations $\left(5,7\right.$, or $\left.9 \mathrm{ng} \times \mathrm{mL}^{-1}\right)$ during intubation. Randomization was performed the day before operation using R software (version 3.1.2, R Foundation for Statistical Computing, Vienna, Austria).

\section{Study procedure}

All patients fasted from midnight. Once in the operating room, the patients were monitored using electrocardiography, pulse oxim- 


\section{COPYRIGHT ${ }^{\odot} 2018$ EDIZIONI MINERVA MEDICA}

PARK

SPI RESPONSE TO INTUBATION WITH REMIFENTANIL

etry, end-tidal carbon dioxide partial pressure, non-invasive blood pressure, and bispectral index (Aspect 2000; Aspect Medical Systems, Inc., Newton, MA, USA) measurements. A reusable SPI sensor (Carescape ${ }^{\circledR}$ B850; GE Healthcare, Milwaukee, WI, USA) was placed on the index finger of the arm opposite to the one used for blood pressure measurement. Neuromuscular transmission was monitored using the $\mathrm{M}-N M T^{\circledR}$ module at the adductor pollicis muscle (Carescape ${ }^{\circledR}$ B850, GE Healthcare, Milwaukee, WI, USA). Throughout the surgery, these data were continuously downloaded to personal computers by using RS232C cables. Following preoxygenation with $100 \% \mathrm{O}_{2}$, anesthesia was induced with propofol and remifentanil, which were administered using a target effect-site concentration-controlled infusion pump (PIONTM TCI; Bionet Co., Ltd., Seoul, Republic of Korea) by using the models suggested by Schnider et al. and Minto et al. ${ }^{16,17}$ After securing adequate mask ventilation, rocuronium $\left(0.6 \mathrm{mg} \times \mathrm{kg}^{-1}\right)$ was administered intravenously. The target effect-site concentrations of propofol were adjusted within a range of $2.5-3 \mu \mathrm{g} \times \mathrm{mL}^{-1}$ to maintain the bispectral index values at less than 60 during the induction and maintenance of anesthesia. The target effect-site concentrations of remifentanil were maintained until the end of intubation. Orotracheal intubation was performed by an experienced anesthesiologist when a train-of-four count was less than two, and a pseudo-steady state of remifentanil between the blood and brain was achieved. The start time of intubation was defined as the time of opening the patient's mouth. After intubation, the target effect-site concentration of remifentanil was changed to $3 \mu \mathrm{g} \times \mathrm{mL}^{-1}$ until the start of surgery. If necessary, ephedrine or atropine was administered during anesthesia to maintain the systolic blood pressure above 80 $\mathrm{mmHg}$ and heart rate above 45 beats $\times \mathrm{min}^{-1}$. The target effect-site concentrations of remifentanil were titrated to maintain stable hemodynamics (systolic blood pressure $>80 \mathrm{mmHg}$ and heart rate $>45$ beats $\times \mathrm{min}^{-1}$ ) within the range of 3-20 $\mathrm{ng} \times \mathrm{mL}^{-1}$ during surgery. The SPI value was calculated using the photoplethys- mographic amplitude (PPGA) and heart beat interval (HBI) extracted from the plethysmographic wave signal of the pulse oximeter, 18 and it was normalised to the range $0-100$ by using a histogram transformation. $\mathrm{SPI}=100$ - $\left(0.7 \cdot \mathrm{PPGA}_{\text {norm }}+0.3 \cdot \mathrm{HBI}_{\text {norm }}\right) .8,12,19$ The value ranges between 0 (low stress response) and 100 (high stress response). A value of 50 represents a mean stress level during anesthesia, and a range between 20 and 50 has been used previously to guide analgesics. ${ }^{11}$

\section{Determination of analgesic potency dose using logistic regression}

Patients showing SPI values equal to or greater than 50 within 5 min after the start of intubation were coded as 0 , whereas patients showing SPI values less than 50 were coded as 1 , which was considered as an analgesia. The relationship between the probability of analgesia and the amount of remifentanil administered before intubation was analyzed using a sigmoid Emax model:

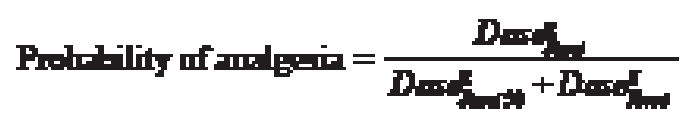

where Dose $_{\text {Remi }}$ is the amount of remifentanil administered before intubation, Dose $e_{\text {Remiso }}$ is the amount of remifentanil associated with a $50 \%$ probability of analgesia, and $\gamma$ is the steepness of the concentration-versus-response relationship.

The likelihood ' $\mathrm{L}$ ' of the observed response ' $R$ ' is described by the following equation:

$$
\mathrm{L}=\mathrm{R} \cdot \operatorname{Prob}+(1-\mathrm{R}) \cdot(1-\text { Prob }),
$$

where Prob is the probability of analgesia. The logistic regression model was fitted using NONMEM $^{\circledR} 7$ level 3 (ICON Development Solutions, Dublin, Ireland). Inter-individual variations in this model could not be successfully estimated with only one observed value per individual (amount of remifentanil administered before intubation). Therefore, a naïve-pooled data approach was used. Model parameters were estimated using the option 'LIKELIHOOD LAPLACE METHOD=conditional' of NONMEM. 


\section{Uncertainty evaluation of the SPI}

The estimation of measurement uncertainty was based on the guide to the expression of uncertainty in measurement. ${ }^{20}$ The measurands in this study were the baseline SPI value in patients without pain scheduled for surgery, and the maximal SPI value after intubation in patients receiving remifentanil with a target effect-site concentration of $7 \mathrm{ng} \times \mathrm{mL}^{-1}$. The baseline SPI value was obtained at the start of propofol administration. Relevant sources $\left(x_{i}\right)$ of uncertainty evaluated in this study were repetitive measurement $\left(x_{\text {rep }}\right)$ as a type-A standard uncertainty, and resolution $\left(x_{\text {res }}\right)$ and calibration of standard $\left(x_{c a l}\right)$ of the SPI as type-B standard uncertainties. The $x_{\text {rep }}$ was calculated using data from 40 patients allocated to receive remifentanil with a target effect-site concentration of $7 \mathrm{ng} \times \mathrm{mL}^{-1}$ during intubation. Standard uncertainty $\left(u_{s}(x)\right)$ is the uncertainty of the result of a measurement expressed as a SD. Therefore, the standard uncertainties for each uncertainty source were estimated by choosing an appropriate distribution of their values. ${ }^{21}$ Combined standard uncertainty $\left(u_{c}(y)\right)$ was calculated using the equation:

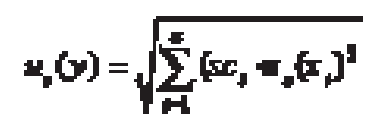

where $u_{s}(x)$ is the standard uncertainty and $s c$ is the sensitivity coefficient, which denotes the uncertainty in $(y)$ arising from the uncertainty in $(x) .{ }^{20} i$ means the number of type A and $\mathrm{B}$ standard uncertainties used in the calculation of the combined uncertainty. The method of obtaining traceability of SPI is described in Appendix I.

\section{Statistics}

A preliminary study to determine the appropriate sample size was conducted by measuring the SPI value of 30 patients allocated to receive one of three remifentanil target effectsite concentrations $\left(5,7\right.$, or $\left.9 \mathrm{ng} \times \mathrm{mL}^{-1}\right)$ during intubation. In the preliminary study, the aver- age differences in the baseline and maximal SPI values after intubation at target remifentanil effect-site concentrations of 5, 7, and 9 $\mathrm{ng} \times \mathrm{mL}^{-1}$ were $19.6,24.5$, and 23.1, respectively, with a pooled SD of 5.8. This study showed that a sample size of 41 patients per treatment arm would be sufficient to detect the differences in SPI values with different effect-site concentrations, with $90 \%$ power at an alpha of 0.05 and considering a $20 \%$ drop-out rate.

A population pharmacodynamic analysis was performed with NONMEM VII level 3 (ICON Development Solutions, Ellicott City, MD, USA) to determine analgesic potency dose of remifentanil. A log-normal model was used to estimate the inter-individual random variabilities (IIV) of pharmacodynamic parameters, and diagonal matrices were applied to estimate the various distributions of $\eta$, where $\eta$ represented the IIV. NONMEM computed the minimum objective function value (OFV), a statistical equivalent to the -2 $\log$ likelihood of the model. An $\alpha$ level of 0.05 , which corresponds to a reduction in the OFV of 3.84 ( $\chi^{2}$ distribution, degrees of freedom $=1$, $\mathrm{P}<0.05$ ), was used to distinguish between hierarchical models. The covariates that were analyzed were age, sex, the presence of hypertension, and administration of ephedrine. Non-parametric bootstrap analysis served to validate the models internally.

\section{Statistical analysis}

Statistical analysis was conducted using SigmaStat, version 3.5 for Windows (Systat Software, Inc., Chicago, IL, USA). Differences of heart rate, systolic blood pressure, and SPI between the groups were analyzed by using Tukey's test followed by one-way analysis of variance (ANOVA) for pairwise comparisons. The data including patient characteristics are expressed as the means (SDs) for normally distributed continuous variables, medians $(25-75 \%)$ for non-normally distributed continuous variables, and counts and percentages for categorical variables. A P value less than 0.05 was considered to indicate statistical significance. 


\section{COPYRIGHT ${ }^{\odot} 2018$ EDIZIONI MINERVA MEDICA}

PARK

SPI RESPONSE TO INTUBATION WITH REMIFENTANIL

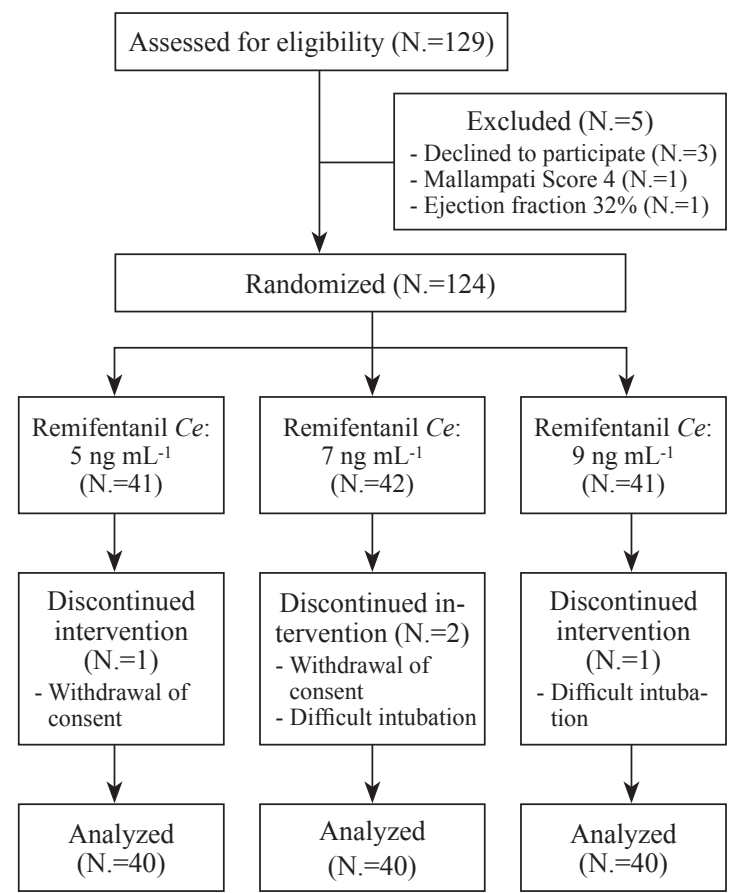

Figure 1.-Consort flow chart of the study. $\mathrm{Ce}$ : effect-site concentration.

\section{Results}

Of the 129 patients screened, five were excluded because they did not meet the inclusion criteria. Of the remaining 124 patients enrolled in this study, four dropped out because of with- drawal of consent $(\mathrm{N} .=2)$ and difficult intubation $(\mathrm{N} .=2)$. Hence, 120 patients were included in the analgesic potency analysis (Figure 1). Patient and intubation characteristics are summarized in Table I. Atropine has not been administered to any patient. As the target effectsite concentration of remifentanil increased, the cumulative amount of remifentanil at the time of intubation increased significantly, as did the number of patients receiving ephedrine before intubation. The time courses of the SPI $5 \mathrm{~min}$ before and after the start of intubation in patients receiving remifentanil with target effect-site concentration-controlled infusion of 5, 7, or $9 \mathrm{ng} \times \mathrm{mL}^{-1}$ are shown in Figure 2. As the target effect-site concentration of remifentanil increased, the maximal value of SPI after intubation decreased. Population pharmacodynamics parameter estimates, inter-individual variability, and median parameter values of the non-parametric replicates of the logistic regression model of SPI are described in Table I. On the basis of these results, we calculated the predicted probability for maintaining the SPI values at less than 50 after intubation, which was plotted against the cumulative amount of remifentanil (Figure 3). The estimate of the cumulative amount of remifentanil associated with a $50 \%\left(\right.$ Dose $\left._{50}\right)$ and $95 \%\left(\right.$ Dose $\left._{95}\right)$ probability of maintaining the SPI values at less

TABLE I.-Patient and intubation characteristics in three randomized groups.

\begin{tabular}{|c|c|c|c|}
\hline Target effect-site concentration of remifentanil $\left(\mathrm{ng} \times \mathrm{mL}^{-1}\right)$ & $\begin{array}{c}5 \\
(\mathrm{~N} . \\
=\end{array}$ & $\left(\begin{array}{l}7 \\
(\mathrm{~N} .\end{array}=40\right)$ & $(\stackrel{9}{\mathrm{~N} .}=40)$ \\
\hline Male/female & $10 / 30$ & $16 / 24$ & $11 / 29$ \\
\hline Age, year & $54.1 \pm 12.6$ & $53.1 \pm 13.6$ & $52.9 \pm 12.2$ \\
\hline Height, $\mathrm{cm}$ & $160.7 \pm 7.6$ & $161.5 \pm 7.6$ & $160.4 \pm 6.8$ \\
\hline Weight, $\mathrm{kg}$ & $60.2(53.7-68.5)$ & $65.8(55.8-71.0)$ & $61.8(54.5-66.8)$ \\
\hline ASA physical status, $1 / 2$ & $24 / 16$ & $21 / 18$ & $25 / 15$ \\
\hline Laryngoscopic view of Cormack and Lehane (I/II/III/IV) & $18 / 18 / 4 / 0$ & $20 / 16 / 4 / 0$ & $17 / 20 / 3 / 0$ \\
\hline $\begin{array}{l}\text { Cumulative amount of remifentanil at the time of } \\
\text { intubation, } \mu \mathrm{g}\end{array}$ & $86.5(82.5-94.2)$ & $130.3(119.5-145.7)^{*}$ & $164.0(158.5-182.6)^{* \dagger}$ \\
\hline $\begin{array}{l}\text { Concurrent disease (none/hypertension/diabetes mellitus/ } \\
\text { others) }\end{array}$ & $25 / 9 / 1 / 4$ & $28 / 7 / 4 / 1$ & $27 / 7 / 2 / 5$ \\
\hline $\begin{array}{l}\text { Number of patients who received ephedrine before } \\
\text { intubation }\end{array}$ & 2 & 1 & $7 \dagger$ \\
\hline
\end{tabular}

Data are expressed as mean (SD), median (25-75\%), or count as appropriate. Parameters were compared using a one-way analysis of variance (ANOVA), Kruskal-Wallis one-way ANOVA on ranks followed by the Tukey Test or $\chi^{2}$ test as appropriate. Laryngoscopic view of Cormack and Lehane. Grade 1: most of the glottis is seen; grade 2: only the posterior portion of the glottis can be seen; grade 3: only the tip of the epiglottis may be seen; grade 4: neither the epiglottis nor the glottis can be seen. Others: asthma, hypothyroidism, history of pulmonary tuberculosis, or hyperthyroidism.

$* \mathrm{P}<0.05$ versus target effect-site concentration of $5 \mathrm{ng} \times \mathrm{mL}^{-1} ;{ }^{\dagger} \mathrm{P}<0.05$ versus target effect-site concentration of $7 \mathrm{ng} \times \mathrm{mL}^{-1}$. 


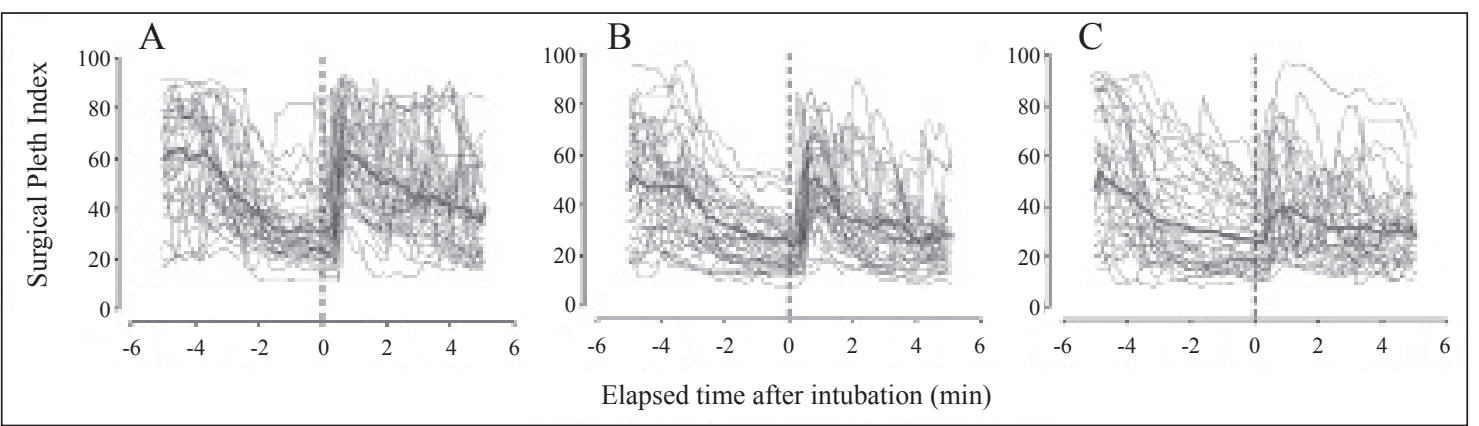

Figure 2.- Time courses of the Surgical Pleth Index (SPI) during the time period 5 min before and after the start of intubation in patients receiving target effect-site controlled infusion of remifentanil at 5 (A), 7 (B), and 9 (C) ng $\times \mathrm{mL}^{-1}$. The individual (black dotted lines) and mean (red solid lines) values are indicated.

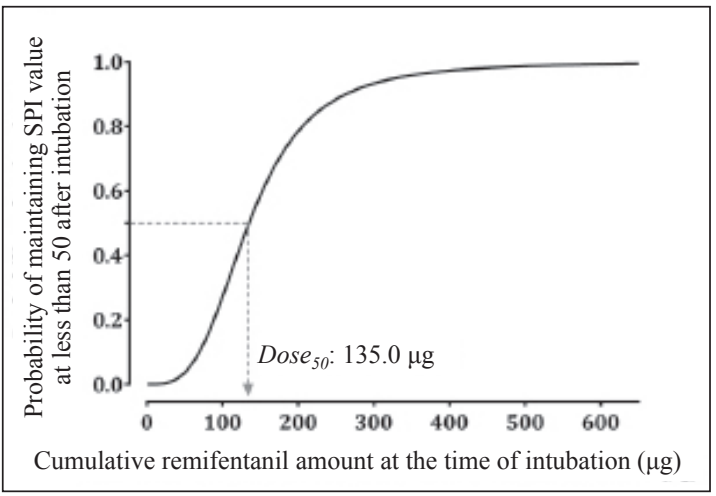

Figure 3.- Predicted probability for maintaining the Surgical Pleth Index (SPI) values at less than 50 after intubation plotted against the cumulative amount of remifentanil.

than 50 after intubation were $135.0 \mu \mathrm{g}$ and $330.4 \mu \mathrm{g}$, respectively. In addition, the changes in the heart rate, systolic blood pressure, and
SPI before and after intubation in patients, and the distribution of the elapsed time to achieve maximal values of heart rate and SPI after the start of the intubation are shown in Figures 4 , 5, respectively. Overall, it was considered appropriate to infuse remifentanil with a target effect-site concentration of $7 \mathrm{ng} \times \mathrm{mL}^{-1}$ for minimizing the noxious stress evoked by intubation while avoiding hypotension.

The uncertainty budget of SPI is summarized in Table III. The baseline and maximal SPI values (type-A standard uncertainty) in patients allocated to receive remifentanil with a target effect-site concentration of $7 \mathrm{ng} \times \mathrm{mL}^{-1}$ during intubation were $54.9 \pm 22.2$ and $54.1 \pm 18.9$, respectively. The resolution of the SPI was 1 , and hence, resolution uncertainty was 0.5 . When converting to standard uncertainty, resolution uncertainty was divided by the square

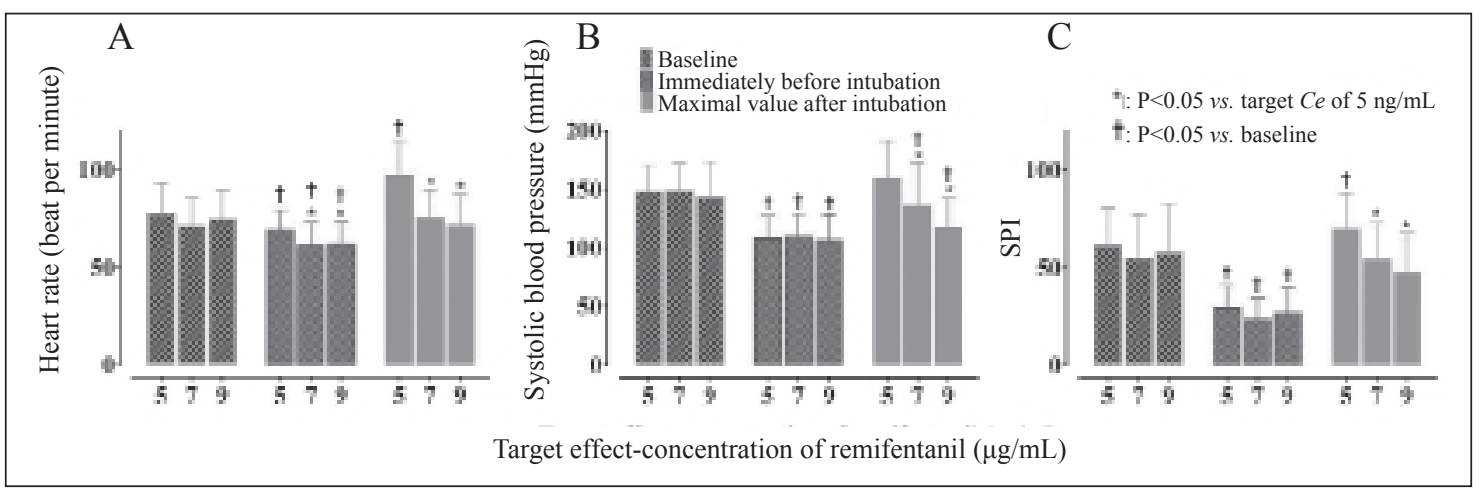

Figure 4.- Change in heart rate (HR), systolic blood pressure (SBP), and Surgical Pleth Index (SPI) before and after intubation in patients receiving target effect-site concentration-controlled infusion of remifentanil at 5 (A), 7 (B), 9 (C) $\mathrm{ng}^{\circ} \times \mathrm{mL}^{-1}$. Baseline values were obtained at the start of propofol administration.

$* \mathrm{P}<0.05$ versus a target effect-site concentration of $5 \mathrm{ng} \mathrm{mL}^{-1} ;{ }^{\dagger} \mathrm{P}<0.05$ versus baseline. 


\section{COPYRIGHT ${ }^{\odot} 2018$ EDIZIONI MINERVA MEDICA}

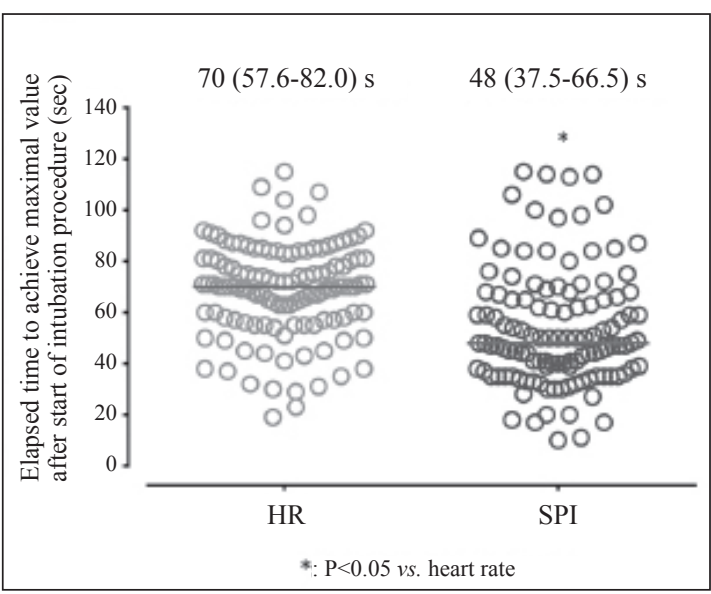

Figure 5.-Distribution of elapsed time to achieve maximal values of the heart rate (HR) and Surgical Pleth Index (SPI) after the start of intubation in patients receiving target effectsite concentration-controlled infusion of remifentanil.

$* \mathrm{P}<0.05$ versus heart rate.

root of 3, assuming a rectangular distribution. In total, 7220 Instantaneous Surgical Pleth Index (ISPI) and SPI data pairs were used to evaluate the traceability of the SPI. The correction value between the SPI calculated from raw PPG and the SPI determined using Carescape $^{\circledR}$ B850 was 0.9 . Generally, calibration uncertainty is assumed to show a normal distribution and is divided by the coverage factor $(k)$ for the given level of confidence. Because the $95 \%$ confidence level calibration uncertainty was 0.9 , the standard uncertainty of calibration was calculated by dividing with the coverage factor 2 . The estimated expanded uncertainty for the baseline and maximal SPI values after intubation in patients scheduled for surgery were 54.9 $\pm 44.4(\mathrm{k}=2)$ and $54.1 \pm 37.9(\mathrm{k}=2)$, respectively, which corresponded to a confidence level of approximately $95 \%$.

\section{Discussion}

Little information is available in the literature on the analgesic potency dose to reduce the surgical stress evoked by intubation

TABLE II.-Population pharmacodynamics parameter estimates (RSE), inter-individual variability (\%CV), and median parameter values (2.5-97.5\%) of the nonparametric replicates of the logistic regression model of the Surgical Pleth Index (SPI).

\begin{tabular}{lccc}
\hline Parameter & Estimate (RSE, \%) & CV (\%) & Median (2.5-97.5\%) \\
\hline Dose $_{50}$ & $135(6.3)$ & - & $135(116-157)$ \\
$\gamma$ & $3.29(22.7)$ & - & $3.33(1.59-5.07)$ \\
\hline
\end{tabular}

Nonparametric bootstrap analysis was repeated 2000 times. Dose ${ }_{50}$ is the cumulative amount of remifentanil associated with a $50 \%$ probability of maintaining the SPI value at less than 50 after intubation, and $\gamma$ is the steepness of the concentration-versus-response relationship. Interindividual variations in this model could not be estimated with only one point per individual. Therefore, a naïve-pooled data approach was used. RSE: relative standard error $=\mathrm{SE} /$ mean $\cdot 100(\%)$; CV: coefficient of variance.

TABLE III.-Uncertainty budget of the Surgical Pleth Index (SPI).

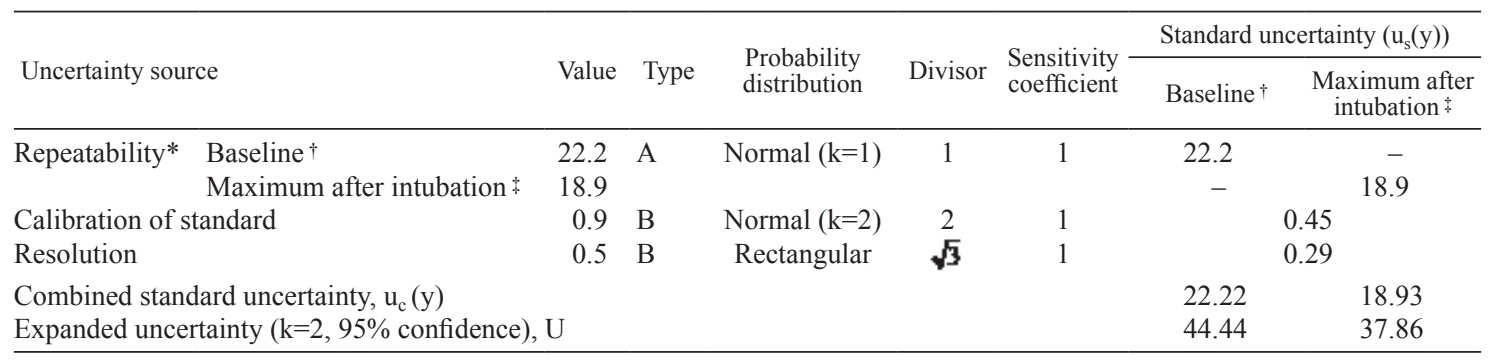

Standard uncertainty: uncertainty of the result of a measurement expressed as a standard deviation, type-A standard uncertainty: method of evaluation of uncertainty by the statistical analysis of series of observations, type-B standard uncertainty: method of evaluation of uncertainty by means other than the statistical analysis of series of observations, Combined standard uncertainty: standard uncertainty of the result of a measurement when that result is obtained from the values of a number of other quantities, equal to the positive square root of a sum of terms, the terms being the variances or covariances of these other quantities weighted according to how the measurement result varies with changes in these quantities, Expanded uncertainty: quantity defining an interval about the result of a measurement that may be expected to encompass a large fraction of the distribution of values that could reasonably be attributed to the measurand, Coverage factor: numerical factor used as a multiplier of the combined standard uncertainty in order to obtain an expanded uncertainty, Measurand: quantity to be measured.

*In total, 40 patients were allocated to receive remifentanil with a target effect-site concentration of $7 \mathrm{ng} \times \mathrm{mL}^{-1}$ during intubation; ${ }^{\dagger}$ the baseline SPI value at the start of propofol administration; the maximal SPI value after orotracheal intubation. 
in patients undergoing general anesthesia with target-controlled infusion of propofol and remifentanil. However, a previous study evaluated the mean effect-site concentration (5.0 ng $\left.\times \mathrm{mL}^{-1}\right)$ of remifentanil for reducing cardiovascular responses to tracheal intubation in $50 \%$ of cases, which was determined using a modified up-and-down sequential allocation technique. ${ }^{6}$ However, the appropriate target effect-site concentration of remifentanil to minimize the noxious stress evoked by intubation was $7 \mathrm{ng} \times \mathrm{mL}^{-1}$ in this study. This discrepancy could be attributed to the differences between the target points of the two studies. Positive response in the previous study was defined as an increase in either the heart rate or mean arterial pressure $\geq 15 \%$ of the mean values measured 2 min before intubation. ${ }^{6}$ In fact, a mean increase in the heart rate $\geq 22 \%$ of the mean values measured 2 min before intubation was observed in the present study. The SPI has been known to be a more effective surrogate marker of analgesia than are the heart rate or mean arterial pressure. ${ }^{7}$ Although target effect-site concentration-controlled infusion has been commonly used in clinical situations, effect-site concentration is not an actual value but a simulated value calculated using a pharmacokinetic model. The effect-site concentration was introduced for collapsing the hysteresis loop between plasma concentration and effect, and it was calculated using pharmacokinetic parameters and the blood-brain equilibration rate constant $\left(k_{e 0}\right) \cdot{ }^{22}$ Hence, the effect-site concentration varies according to the type of pharmacokinetic model and surrogate measure of effect used for estimating $k_{e 0}$. The dose administered depends on the pharmacokinetic model and $k_{e 0}$ programmed into a target-controlled infusion system even if the same target effect-site concentration value was maintained during anesthesia. Therefore, knowing the dose of remifentanil required to maintain the SPI value at less than 50 after intubation during anesthesia induction would be useful.

The SPI value may have been reaching its maximal value earlier than the heart rate does after intubation because of the SPI algorithm used. A noxious stimulus causes nociception, thereby producing a sudden but temporary depression of the PPGA due to peripheral vasoconstriction induced by sympathetic activation. ${ }^{18}$ The weighting coefficient of PPGA $\mathrm{norm}_{\text {}}$ was about twice as large as that of $\mathrm{HBI}_{\text {norm }}$, indicating that the PPGA became a more important consideration than HBI when calculating the SPI value.

The fundamental idea of uncertainty is a relatively new concept in the history of metrology, because error analysis has been long established in metrology. ${ }^{14}$ It is now widely used in the physiological, biochemical, and physical fields when known or suspected elements of error have been assessed and/or proper corrections have been applied. The important point of uncertainty is that no measurement is exact or certain. It is necessary to consider this uncertainty when making a measurement because all kinds of measurements have uncertainty. The sources of uncertainty could be categorized as type-A or type-B.14 Type-A standard uncertainty is calculated using statistical analysis of repeated measurements, while type-B standard uncertainty is estimated using any other available information. If we measure the weight of a patient 10 times and analyzes the results, this would be a type-A standard uncertainty. Considering the calibration certificate and resolution of a scale used for measuring weight would be a type-B uncertainty. Type-A standard uncertainty and type-B standard uncertainty should be each calculated at the coverage factor $(\mathrm{k})$ of $1(\mathrm{k}=1)$. $\mathrm{k}$ of 1 means standard deviation in general statistics. The two types of standard uncertainty are combined to be calculated as combined standard uncertainty. Expanded uncertainty is determined by multiplying by the appropriate coverage factor. In general, the coverage factor of $2(\mathrm{k}=2)$ is mainly used, which corresponds to a confidence level of approximately $95 \% .{ }^{21}$

In this study, the contribution of type-B standard uncertainties of the SPI was negligible because type-A standard uncertainty was the major contributor, indicating that the SPI values showed striking inter-individual variabili- 


\section{COPYRIGHT ${ }^{\odot} 2018$ EDIZIONI MINERVA MEDICA}

PARK

SPI RESPONSE TO INTUBATION WITH REMIFENTANIL

ties irrespective of the noxious stimulation. Large inter-individual variabilities of SPI values were also observed in previous studies.7,12 Therefore, we may no longer need to consider type-B standard uncertainties of a measurand showing large inter-individual variability.

\section{Limitations of the study}

A limitation of this study was the administration of ephedrine, which may have affected the SPI value. However, the administration of ephedrine was inevitable for maintaining stable hemodynamics. Sub-group analysis was performed by dividing the patients who received ephedrine and those who did not. Time courses of the SPI during the time period $5 \mathrm{~min}$ before and after the start of intubation in patients who received ephedrine and those who did not were presented in Supplementary Figure 1, online content only. 1S. As shown in Table I and Supplementary Figure 1 , the number of patients receiving ephedrine was small (10/120, 8.3\%). SPI changes were similar for patients $(\mathrm{N} .=7)$ administered with $9 \mathrm{ng} \times \mathrm{mL}^{-1}$ despite the use of ephedrine. Moreover, there seemed to be little difference in the analgesic potency dose of remifentanil in patients who did not receive ephedrine (Dose 50 : $141 \mu \mathrm{g})$. Also, ephedrine administration was not a significant covariate on pharmacodynamic parameters. It resulted in improvement in the objective function value $(3.53, \mathrm{P}=0.06$, degree of freedom=1), compared with the basic model (number of model parameters $=2$ ). Considering these points, we suggest that ephedrine might have little effect on determination of the analgesic potency dose of remifentanil to maintain the SPI values at less than 50 after intubation. Another limitation of this study is the estimation of the correction value of the SPI by using raw PPG signals. In general, calibration uncertainty is calculated using a calibration certificate supplied by the manufacturer. However, it is hard to obtain in the case of the SPI, which is a processed biosignal index. Moreover, the provision of a calibration certificate of the SPI is not compulsory. As previously mentioned, because the type-A standard uncertainty of the
SPI was the major contributor to the combined variance, the estimation of the correction value might have little influence on the calculation of the combined standard uncertainty.

\section{Conclusions}

In conclusion, the analgesic potency dose of remifentanil to maintain the SPI values at less than 50 after intubation was $135 \mu \mathrm{g}$ in patients undergoing general anesthesia with target-controlled infusion of propofol and remifentanil. The authors suggest that this study can contribute to the SPI-guided use of analgesics because SPI-guided analgesic use during general anesthesia is not prevalent in the clinical field. Furthermore, more studies will be needed to confirm the efficacy of SPI-guided use of analgesics in various anesthetic methods including inhalation anesthesia. In addition, considering the type-B standard uncertainties of a measurand showing a large inter-individual variability may not be necessary.

\section{Key messages}

- Little is known about the analgesic potency of remifentanil to minimize surgical stress evoked by intubation undergoing general anesthesia.

- The estimated cumulative amount of remifentanil associated with a $50 \%$ and $95 \%$ probability of maintaining the SPI values at less than 50 after intubation were $135.0 \mu \mathrm{g}$ and $330.4 \mu \mathrm{g}$.

- The consideration of the type-B standard uncertainties of a measure and showing a large inter-individual variability may not be necessary.

\section{References}

1. Struys MM, De Smet T, Glen JI, Vereecke HE, Absalom AR, Schnider TW. The History of Target-Controlled Infusion. Anesth Analg 2016;122:56-69.

2. Parker SD, Breslow MJ, Frank SM, Rosenfeld BA, Norris EJ, Christopherson R, et al. Catecholamine and cortisol responses to lower extremity revascularization: correlation with outcome variables. Perioperative Ischemia 


\section{COPYRIGHT ${ }^{\odot} 2018$ EDIZIONI MINERVA MEDICA}

Randomized Anesthesia Trial Study Group. Crit Care Med 1995;23:1954-61.

3. Myles PS, Hunt JO, Fletcher H, Watts J, Bain D, Silvers A, et al. Remifentanil, fentanyl, and cardiac surgery: a double-blinded, randomized, controlled trial of costs and outcomes. Anesth Analg 2002;95:805-12.

4. Kahl M, Eberhart LH, Behnke H, Sanger S, Schwarz U, Vogt $\mathrm{S}$, et al. Stress response to tracheal intubation in patients undergoing coronary artery surgery: direct laryngoscopy versus an intubating laryngeal mask airway. J Cardiothorac Vasc Anesth 2004;18:275-80.

5. Guignard B, Menigaux C, Dupont X, Fletcher D, Chauvin $\mathrm{M}$. The effect of remifentanil on the bispectral index change and hemodynamic responses after orotracheal intubation. Anesth Analg 2000;90:161-7.

6. Albertin A, Casati A, Federica L, Roberto V, Travaglini $\mathrm{V}$, Bergonzi $\mathrm{P}$, et al. The effect-site concentration of remifentanil blunting cardiovascular responses to tracheal intubation and skin incision during bispectral indexguided propofol anesthesia. Anesth Analg 2005;101:12530 , table of contents.

7. Gruenewald M, Ilies C, Herz J, Schoenherr T, Fudickar A, Hocker J, et al. Influence of nociceptive stimulation on analgesia nociception index (ANI) during propofol-remifentanil anaesthesia. Br J Anaesth 2013; 110:1024-30

8. Huiku M, Uutela K, Van Gils M, Korhonen I, Kymalainen M, Merilainen P, et al. Assessment of surgical stress during general anaesthesia. Br J Anaesth 2007;98:447-55.

9. Gruenewald M, Meybohm P, Ilies C, Hocker J, Hanss R, Scholz J, et al. Influence of different remifentanil concentrations on the performance of the surgical stress index to detect a standardized painful stimulus during sevoflurane anaesthesia. Br J Anaesth 2009; 103:586-93.

10. Chen X, Thee C, Gruenewald M, Ilies C, Hocker J, Hanss $\mathrm{R}$, et al. Correlation of surgical pleth index with stress hormones during propofol-remifentanil anaesthesia. ScientificWorldJournal 2012;2012:879158.

11. Chen X, Thee C, Gruenewald M, Wnent J, Illies C, Hoecker J, et al. Comparison of surgical stress indexguided analgesia with standard clinical practice during routine general anesthesia: a pilot study. Anesthesiology 2010;112:1175-83.

12. Gruenewald M, Willms S, Broch O, Kott M, Steinfath
M, Bein B. Sufentanil administration guided by surgical pleth index vs standard practice during sevoflurane anaesthesia: a randomized controlled pilot study. Br J Anaesth 2014;112:898-905.

13. Bergmann I, Gohner A, Crozier TA, Hesjedal B, Wiese $\mathrm{CH}$, Popov AF, et al. Surgical pleth index-guided remifentanil administration reduces remifentanil and propofol consumption and shortens recovery times in outpatient anaesthesia. Br J Anaesth 2013;110:622-8.

14. [No authors listed]. International vocabulary of basic and general terms in metrology (VIM). Third edition. 2004, chapter 2, page 13

15. Squara P, Imhoff M, Cecconi M. Metrology in medicine: from measurements to decision, with specific reference to anesthesia and intensive care. Anesth Analg 2015;120:66-75

16. Schnider TW, Minto CF, Gambus PL, Andresen C, Goodale DB, Shafer SL, et al. The influence of method of administration and covariates on the pharmacokinetics of propofol in adult volunteers. Anesthesiology 1998;88:1170-82.

17. Minto CF, Schnider TW, Egan TD, Youngs E, Lemmens HJ, Gambus PL, et al. Influence of age and gender on the pharmacokinetics and pharmacodynamics of remifentanil. I. Model development. Anesthesiology 1997;86:10-23

18. Korhonen I, Yli-Hankala A. Photoplethysmography and nociception. Acta Anaesthesiol Scand 2009;53:975-85.

19. Bonhomme V, Uutela K, Hans G, Maquoi I, Born JD, Brichant JF, et al. Comparison of the surgical Pleth Index with haemodynamic variables to assess nociceptionanti-nociception balance during general anaesthesia. $\mathrm{Br} \mathrm{J}$ Anaesth 2011;106:101-11.

20. Joint Committee for Guides in Metrology. Evaluation of measurement data - Guide to the expression of uncertainty in measurement (GUM). JCGM 100:2008.; [Internet]. Available from: https://www.bipm.org/en/publications/ guides/gum.html [cited 2017, Oct 20].

21. Rami L, Canalias F. An approach to establish the uncertainty budget of catalytic activity concentration measurements in a reference laboratory. Clin Chem Lab Med 2015;53:743-51.

22. Sneyd JR, Rigby-Jones AE. Effect site: who needs it? Br J Anaesth 2007;98:701-4.

Authors' contributions. - Ji Hyun Park and Dong-Hee Kim contributed equally to this work as first authors.

Funding.- This work was supported by a Student Research Grant (15) from the University of Ulsan College of Medicine and the Ministry of Trade, Industry and Energy of Korea (No. 10047088), Seoul, Korea.

Conflicts of interest.-The authors certify that there is no conflict of interest with any financial organization regarding the material discussed in the manuscript.

Article first published online: September 11, 2017. - Manuscript accepted: September 1, 2017. - Manuscript revised: July 21, 2017. Manuscript received: March 13, 2017.

For supplementary materials, please see the online version of this article at www.minervamedica.it 


\section{COPYRIGHT ${ }^{\odot} 2018$ EDIZIONI MINERVA MEDICA}

PARK

SPI RESPONSE TO INTUBATION WITH REMIFENTANIL

\section{SUPPLEMENTARY MATERIALS}

\section{Method of obtaining traceability of SPI}

We estimated the SPI algorithm by using raw photoplethysmographic (PPG) signals for establishing its traceability, because the manufacturer GE Healthcare did not provide any traceability data for the SPI. Therefore, we calculated a new algorithm, instantaneous surgical pleth index (ISPI), based on the photoplethysmographic amplitude (PPGA) and photoplethysmographic pulse interval (PPI). To extract the PPGA and PPI reliably from the PPG signals, which could be contaminated by noise, the PPG signal samples acquired at a sampling frequency of $300 \mathrm{~Hz}$ were filtered to obtain smoothed PPG samples while minimising the number of suspicious or distorted waveform notches. Zero-phase filtering was conducted by applying forward and reverse paths of the second order low-pass Butterworth filter with a $5-\mathrm{Hz}$ cut-off frequency in sequence. Then, the PPGA and PPI were automatically extracted from the filtered PPG samples. The PPGA was derived from the abruptly changing slope points, which were calculated by squaring the first derivative of the PPG samples. The squaring process accentuates the changing slope so that the appropriately defined threshold can regularly extract the maximum slope point with respect to one period of PPG samples from the squared derivative samples. From this point, the right-half period search window (forward direction) and the left-half period search window (reverse direction) searched for the maximum and minimum points as the peak and trough amplitudes, respectively. The PPGA was defined as the difference between the peak and trough amplitudes. The PPI was the time interval corresponding to the number of samples between adjacent maximum slope points. The extracted PPGA and PPI signals could be affected by amplitude and interval variations associated with differences in PPG devices and individual physiology. Therefore, the amplitude and interval variations were compensated for by suppressing device-related and individual variations in order to extract a reliable ISPI. The distributions of the extracted PPGA and PPI were assumed normal, because precise estimation of PPGA and PPI distributions under limited sample data remains controversial. The cumulative distribution function $(\mathrm{CDF})$ related to normal distribution could be calculated by estimating the mean and SD of the PPGA and PPI signals. Since the area of the CDF of normal distribution was 1 , the amplitude and interval variations were compensated for by mapping them to the CDF output. The maximum and minimum CDF outputs were bound to 1 and 0 , respectively, according to the following equation:

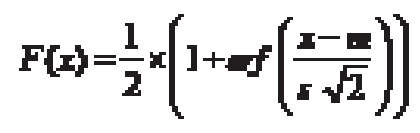

where $x$ corresponds to the PPGA and PPI values, and $\mu, \sigma$, erf, and $F(x)$ are the mean, SD, error function (Gauss error function), and CDF output (normalising function), respectively.

The individual mean and SD of the PPGA and PPI were estimated using 2-3 min of front samples of normal PPG signals, and then the group mean and SD were calculated by averaging the individual means and SDs. The normalisation of PPGA was performed using linearly weighted summing of the individual PPGAs and group PPGA. The normalization of PPI was performed similarly.

$$
\begin{gathered}
P P G A_{\text {normalise }}=F\left(0.7 \cdot P P G A_{\text {individual }}+0.3 \cdot P P G A_{\text {group }}\right) \\
P P I_{\text {normalise }}=F\left(0.7 \cdot P P I_{\text {individual }}+0.3 \cdot P P I_{\text {group }}\right) \\
I S P I=100-\left(30 \cdot P P I_{\text {normalise }}+70 \cdot P P G A_{\text {normalise }}\right)
\end{gathered}
$$

The coefficients of 0.3 and 0.7 in SPI are scaled to 30 and 70 to match the normalized range of $0-1$ to the percentage range of $0-100 \%$, respectively. Sample-by-sample application of the normalised signals was used to estimate the ISPI, and the SPI was obtained by averaging $1 \mathrm{~min}$ of the ISPI. 


\section{COPYRIGHT ${ }^{\odot} 2018$ EDIZIONI MINERVA MEDICA}
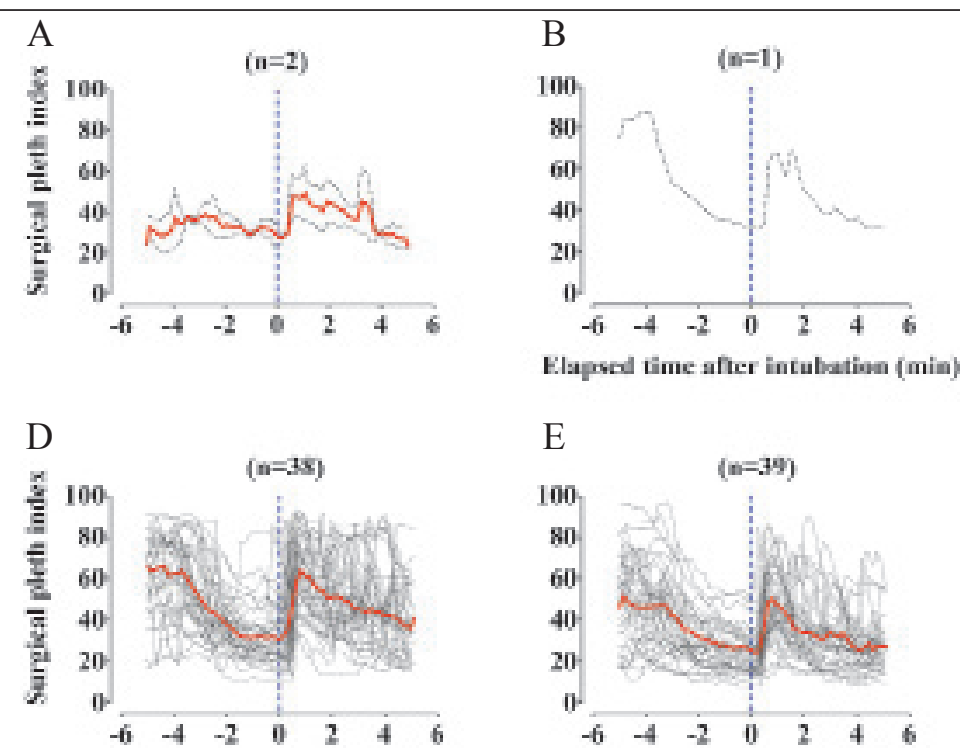

Elapsed time after intubation (min)
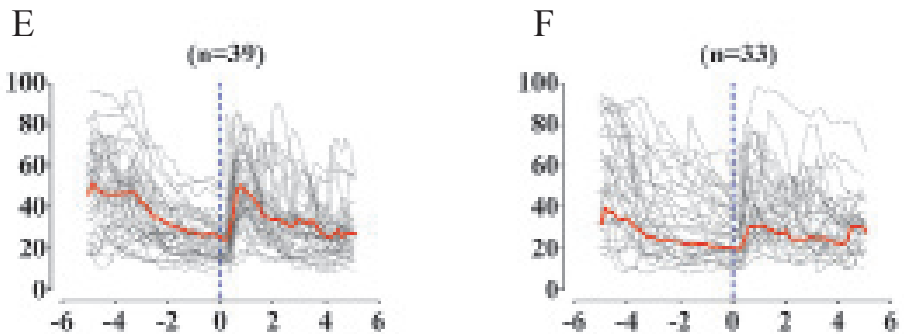

Elapsed time after intubatinn (min)

Supplementary Figure 1.-Time courses of the SPI during the time period 5 min before and after the start of intubation in patients who received ephedrine $(\mathrm{A}, \mathrm{B}, \mathrm{C})$ and those who did not $(\mathrm{D}, \mathrm{E}, \mathrm{F})$. Patients received target effect-site concentration controlled infusion of remifentanil at $5(\mathrm{~A}, \mathrm{D}), 7$ (B, E), $9(\mathrm{C}, \mathrm{F}) \mathrm{ng} \times \mathrm{mL}^{-1}$. The individual (black dotted lines) and mean (red solid lines) values are indicated. 